\title{
Critical Review of the Plight of the Ghanaian Aged
}

\author{
Irene Korkoi Aboh M.Phil.(PH), RN ${ }^{1.2}$, Professor Busisiwe P. Ncama PhD, MCur ${ }^{1}$ \\ School of Nursing and Public Health, University of KwaZulu-Natal, Howard College, Durban, South Africa. \\ University of Cape Coast, College of Education Studies, Faculty of Science and Technology Education, \\ Department of Health Sciences
}

\begin{abstract}
The elderly reaching retirement age enter a period of poverty and deprivation, poor access to health care and poor nutrition. These situations leave them with insufficient personal savings to meet their daily needs. This paper critically review literature on reports on how the aged are handled in the contemporary era of scarcity of resources in the face of growing population of the aged and some of the issues facing the aged in Ghana. Aged care is facing a lot of challenges for both the aged and caretakers. This paper reviewed literature on studies done by other researchers using the engine search through Google scholar, PubMed, ScienceDirect and EBSCOhost to outline few problems. Results showed that caring for the aged is difficult for Ghanaian families in the face of scarce resources. It is strongly recommended that the government of Ghana looks at how best to care for its aged citizens who have also contributed immensely to the present growing economy.
\end{abstract}

Keywords: Aged, care, elderly, Ghana, older people, policy

\section{Introduction}

Population ageing is now recognized as a global issue of increasing importance, and has many implications for health care and other areas of social policy. However, these issues remain relatively underresearched, particularly in poorer countries where there is a dearth of specific, policy [1] [2]. While the United Nations uses 60 years to refer to the elderly, developed countries where life expectancy is high, the age of retirement from active public economic activity is 65 years. The elderly is defined as persons aged 65 years and above and vice versa for developing countries [3]. Studies by [4] [5] assessed the aging process by measuring clinical and functional variables on older people about what constituted their health and contributed to it [6]. To healthy aging, older peoples' health means going and doing something meaningful, which required four components such as something worthwhile to do, balance between abilities and challenges, appropriate external resources, and personal attitudinal characteristics which constituted "positive attitude" vs. "poor me" [6]. Pertinent knowledge about factors relating to low life satisfaction among older people with reduced self-care capacity is important in health care and nursing so that care is adapted to the needs and perspective of life, [7]. There has been much focus on isolated aspects such as pain in relation to life satisfaction among older people and less among those with reduced general self-care capacity [7]. A seldom discussed practices is the longdistance family relations and aged care as an importance key variable in the comparisons of the care exchange; which highlight the importance of considering the role of homeland kin and communities in discussions of migration [8].

\section{Emerging Problems on Care of the Aged}

Elderly care, or simply eldercare or aged care is the provision of special needs and attention unique to older citizens; a term which encompasses services such as assisted living, adult day care, long term care, nursing homes, hospice care, and home care [9]. Globally the care for the elderly is found to be wide because of different cultural perspectives however this care is limited to any one practice, such as assisted care [10]. The form of elderly care provided varies greatly among countries and is changing rapidly [10]. Even within the same country or region, differences exist with respect to the care for the elderly. It has been observed that, the elderly consumes the most health expenditures out of other age groups, an observation that shows similarities in eldercare [11]. This accounts for an increasingly large proportion of the elderly especially in developing nations. Elderly care emphasizes the social and personal requirements of senior citizens who need some assistance with daily activities, but desire to age with dignity [12]. Traditionally, elderly care is the responsibility of family members and care is provided within the extended family home, but in recent times, elderly care is now being provided by the state or charitable institutions [13]. The reasons for this change include decreasing family size, greater life expectancy of elderly people, the geographical dispersion of families, and the tendency for women to be educated and work outside the home [14]. Many elderly people gradually lose functioning ability and require either additional assistance in the home or move to an eldercare facility. The adult children of these elders often face a difficult challenge in helping their parents make the right choices. Assisted living is one option for the elderly who need assistance with everyday tasks. It costs less than nursing home care but it is still considered expensive for most people. Home care services may allow older people to live in their own home for a longer period. 


\section{Elderly Care in Ghana}

In Ghana, the National Disability Policy caters for the welfare of the aged [15]. The policy assumes that ageing process exposes individuals to increasing risk of illness and disability. Although a developing country with a weak but promising economy, the ageing population of Ghana is mostly associated with disability [15]. The role of the church, family structures and childlessness, conditions and relationships in the aged families are a great concern regarding how the elderly in Ghana perceive their own life situation and their role in the family, church and society [16]. Family is very important in the traditional Ghanaian society and the main role of the elderly has been to function as advisors in every day matters, as well as taking important decisions. However, this role has changed and the everyday function is on its way to disappear. The elderly is only consulted on important issues; most of them feeling lonely especially those without children and they do not feel they are as respected as they should be, leading to a great difference between the elderly in the city and their counterparts in the village [17].

The perfect ideas and practices of caring for the elderly people in rural Kwahu communities of Ghana disclosed the kind of care old people receive. This care is interpreted as 'who provides those care', 'on what basis do people care for the old', 'under what obligation is it done and 'what are the changes taking place in the field of care for old people'. And these are issues to be considered. Respect and reciprocity of care takes a central position in accounts of rendering care and lack of care [18]. With the principle of reciprocity, decline in the rendering of care has been supported by two major shifts that is a declining resource capacity of the young to provide support and a shift in the basis of support toward an increasing dependence on parents' past conduct. For the Ghanaian populace, normal aged expectations emphasizing self-reliance in old age are emerging because of the decline in mortality [18]. Van der Geest, (2002) maintained that, the position of money to the elderly and their relatives in Southern Ghana highlights money as a core symbol in daily life by which people measure the value of their relationships. It is not used to keep people at bay but rather to establish and maintain social bonds and to secure care in old age. Not having money engenders respect, discloses failure and shame. Giving money is a way of 'paying' respect and shows affection and care for the elderly as a sign of a successful life.

\section{Social Issues and the Aged}

The role of social welfare in Africa by looking at the position of the family in the face of all the social changes taking place is that, the role of the traditional African family may be broadly subdivided into its social role, economic role and its role as an agent for the transmission and renewal of sociocultural values [19] [20]. There is a complex interaction between members of the family and the community. The economic, political and sociocultural values of present-day Africa, with its sprawling urban centres and industrial zones, differ increasingly from its traditional values [19] [20]. The family is disintegrating and social change has brought in its wake a host of new social problems which the social welfare services are not adequate to meet. Social welfare on one hand is viewed as a non-productive activity and therefore accorded a low priority in national development planning and resource allocation. In such contexts, the scope of social policy is limited and cannot deal with the critical problems of mass poverty and deprivation afflicting most African people, especially in rural areas [19] [20]. Using Ghana as an example, key issues examined and recommendations made for effective social policies and programmes need to be incorporated centrally into national development plans [3].

To the Ghanaian aged, funerals in recent times are flooded with political reputation of the living instead of looking at religion and the deceased. Views of the elderly on personal observations and attendance at funerals showed that funerals are first and foremost occasions for the family to affirm its prestige and to celebrate its excellence. When thinking about their own funeral, the elderly is ambivalent [22]. On the one hand, they criticize the overemphasized funeral expense blaming it on policy than take proper care of them during their life time. Even though, they would certainly not want to turn the tables, for them, a poor funeral would be an unbearable disgrace. The elderly has agreed on the family being the most important aspect in their lives, since spending time and enjoying the company brings some sort of joy and safety because there is always someone around. They feel more belonged within the church and experience spirituality which draws them closer to God. But society's respect and support for the aged have somewhat dwindled [3]. The elderly being cared for, are exempted from active activities of physical, psychological and biological changes because of ageing. Also, they play the role of advisors within the family and society [17]. By improving elderly care, the government of Ghana has been entrusted to provide community centres that will serve both purposes as a socialization place and a free health check-up centres [15]. Loss of rights, victimization, and other grave problems face the elderly person who has made little or no plans for personal and property management in the event of disability or death [22].

Through the Ministry of Employment, the Social Welfare has developed a National Ageing Policy and an Implementation Action Plan which has recommended that older persons in Ghana should continue to enjoy great deal of respect and dignity within the traditional settings of the country. However, it has been noted that there are pockets of reported cases of abuse against the elderly [23]. Similarly, low levels of wages and salaries 
and the informal characteristics of the economy, has created a pathway where most people age into poverty. This may be interpreted as a violation of the economic rights of older persons in Ghana. Some older persons living in family houses/rooms have been ejected by their younger generation and these houses/rooms rented out for profit, [3]. Despite their growing numbers, the health and care of the elderly population has not been accorded optimal attention in Ghana and in other low-income countries [24]. Increasing neglect, physical abuse and poverty are the major challenges facing older persons in Ghana. The 1992 Republican Constitution guarantees fair and equal treatment to all citizens without recourse to their ethnicity, creed, political affiliation, social status nor age [25]. This means that the elderly like other social groups in Ghana have the right to enjoy all the basic human rights including equal access to public services [23]. Due to cultural factors and the high level of in formalization of the Ghanaian economy, older persons especially women are usually the most vulnerable, most susceptible to abuse and violence and discriminated against based on gender.

The National Health Insurance Scheme is age sensitive to some extent, older persons 70 years and above received primary health care under the scheme without paying premium, [15]. This is to ensure increased access to health care for older persons in Ghana. There are no Geriatric Centre in Ghana therefore older persons in Ghana enjoy general facilities of transportation like other groups of society without distinction. Buildings are hardly designed or constructed with older persons in view. Care for the aged is just like care for anybody else in health care facilities seeking health care, [15]. Age-friendly environments are also important to ensuring the safety, health and independence of older persons. Affordable housing and accessible transportation can help older persons remain active members of society. Many older persons eventually require care, a responsibility that typically falls on their families. But declining fertility and rapid urbanization have changed traditional family relations, sometimes increasing burdens on the traditional family support network. As the number of older people grows, families will need support with caregiving. And it is increasingly important to ensure social protection for the elderly [26]. Older persons who have difficulties with the most essential daily activities have a personal caregiver. However, those who can carry on basic activities of daily living on their own but have mobility problems unfortunately do not have a caregiver assisting them. A typical period of dependence, when a caregiver is needed to carry out daily living activities ironically when the percentage of older persons who report their health as good or very good is recently increasing [27].

The rural-urban migration and international migration of working population have created social distances between the working population and their aged relatives thereby increasing the number of neglected and isolated older persons in the communities [23]. The document further commented that Older persons sometimes are responsible for nurturing children of migrants. Remittances from migrant relations are often not adequate and at times irregular therefore worsening the economic status of older persons. There are however isolated cases of migrants making significant contributions to the upkeep of relatives. As the pension scheme allowances during retirement are increased contributors make involuntary contribution in addition to their mandatory contributions, a social protection programmes targeting the poor without special attention to the peculiar needs of older persons [23]. Existing documentations such as legislation, policies and programmes addressing violence and abuse against older persons posits that older women in Ghana are the most vulnerable because of cultural practices and traditions. A sizeable number of cases of abuse and discrimination against older persons in Ghana involve women. They are mostly accused of witch-craft. In the Northern part of the country, hence the camps accommodating those accused of witch-craft. The very important questions to ask are what kind of assisted care is given to the aged in our homes, what existing cultural practices encourage care for the aged, what strategies are put in place by the individual towards ageing and what resources are available to be factors to motivate assisted care of the aged, [23].

\section{Conclusion}

The extended family system in Ghana ensures that the aged are cared for by the younger members of the family. It is like a security system which obliged its members to assist each other in times of crises and share the achievement and glory that each member brings [28]. Older persons depend on the younger generations for financial, social health care supports. However, it has been pointed out that traditional source of support is dwindling in the face of the ever-growing members of the family [29]. The storm of modernization, migration and urbanization is partly responsible for the gradual changeover from the extended to nuclear system thereby shifting a greater part of care to the nuclear family, which is ill prepared to carry the responsibilities of care for the aged. However, the aged would like to live and die in an environment they consider home where cares in these areas are desired. Children and significant others are saddled with the care of their beloved relatives. Few caretakers have abandoned their families to look after aged parents as a reciprocation of care.

\section{Acknowledgement}

We are grateful to Akon Emmanuel Ndiok University of Calabar, Nigeria and Dr Precious A. Mattah of University of Cape Coast, Ghana for their attention and support in moulding the manuscript. 


\section{References}

[1]. Lloyd-Sherlock, P. (2000) Population Ageing in developed and developing regions: implications for health policy. Social science \& medicine, 51: 887-895.

[2]. Oeppen, J. and Vaupel, JW (2002) Broken limits to life expectancy, Science, 296: 1029 - 1031) doi:10.1126/science.1069675

[3]. Ghana Statistical Service (2013) 2010 Population \& Housing Census Report: The Elderly in Ghana, Ghana Statistical Service, Accra, Ghana, 26-48.

[4]. Manton KG and Gu X (2001) Changes in the prevalence of chronic disability in the United States black and nonblack population above age 65 from 1982 to 1999. Proceedings of the National Academy of Sciences, 98(11):6354-6359.

[5]. Freedman VA, Martin LG and Schoeni RF (2002) Recent trends in disability and functioning among older adults in the United States: a systematic review. Jama, 288: 3137-3146.

[6]. Bryant L L, Corbett KK and Kutner JS (2001) In their own words: a model of healthy aging. Social Science \& Medicine, 53: 927941.

[7]. Borg C, Hallberg I R and Blomqvist K (2006) Life satisfaction among older people (65+) with reduced self-care capacity: the relationship to social, health and financial aspects. Journal of clinical nursing, 15: 607-618.

[8]. Baldassar L. (2007) Transnational families and aged care: the mobility of care and the migrancy of ageing. Journal of ethnic and migration studies, 33: 275-297.

[9]. Sundström G. (1982) The Elderly, Women's Work and Social Security Costs. Acta Sociologica $25 \quad 1: 21-38$.

[10]. Department of Health and Ageing (DHA). (2010) Supporting Australians to live well at the end of life-National Palliative Care Strategy 2010, Canberra, Australian Capital Territory Australian Health Ministers, Retrieved February 16, 2017, from http://www.health.gov.au/internet/main/publishing.nsf/Content/533C02453771A951CA256 F190013683B/\$File/NationalPalliativeCareStrategy.pdf

[11]. Cubit KA and Meyer C. (2011) Aging in Australia, Gerontologist 51(5); 583-589 DOI:https// doi.org/10.1093/geront/gnr/082. Retrieved on February 162017.

[12]. Kim K. and Antonopoulos R. (2011). Unpaid and Paid Care: The Effects of Child Care and Elder Care on the Standard of Living. Levy Economics Institute.

[13]. Ting GHY and Woo J. (2009) "Elder care: is legislation of family responsibility the solution?" hkag publications.

[14]. Huang S, Thang LL and Toyota M. (2012) "Transnational Morbidities for care: Rethinking the dynamics of care in Asia". Global Networks 12 (2): 129. doi:10.1111/j.1471-0374.2012.00343.x.

[15]. Ghana Statistical Service (GSS) (2012) 2010 Population and Housing Census, Summary Results of Final Report. Ghana Statistical Service, Accra, Ghana.

[16]. Karlberg T. (2003) Elderly People in Ghana, About Roles and Life Situations from their own Perspective. Örebro Theological $\begin{array}{llll}\text { Seminary. } & \text { Accessed } & 23.10 .2013 . & \text { Published }\end{array}$ http://www.orebromissionsskola.se/bilder/nya_uppsatser/FSP\%200708\%20Therese\%20

Karlberg\%20Elderly\%20People\%20in\%20Ghana.pdf

[17]. Dosu G. (2014) Elderly Care in Ghana. hkag publications

[18]. Van DER Geest S. (2002) Respect and reciprocity: Care of elderly people in rural Ghana. Journal of Cross-Cultural Gerontology, $17: 3-31$.

[19]. Aboderin I. (2004) Decline in material family support for older people in urban Ghana, Africa: Understanding processes and causes of change. The Journals of Gerontology Series B: Psychological Sciences and Social Sciences, 59: S128-S137.

[20]. Ogwumike FO and Aboderin I. (2005) Exploring the links between old age and poverty in Anglophone West Africa: evidence from Nigeria and Ghana. Generations Review, 15: 7-15.

[21]. Van DER Geest S. (2000) Funerals for the living: Conversations with elderly people in Kwahu, Ghana. African Studies Review, 43: 103-129.

[22]. Plotkin K and Roche J. (2000) The future of home and hospice care: Linking interventions to outcomes. Home Healthcare Now, 18(7): 442-449.

[23]. Government of Ghana/Ministry of Employment and Social Welfare, (GOG/MESW) (2010) National ageing policy: 'Ageing with Security and Dignity' JULY 2010 - (Unpublished).

[24]. Biritwum R, Mensah G, Yawson A. and Minicuci N, (2013), Study on global AGEing and adult health (SAGE) Wave 1, The Ghana National Report, World Health Organisation. Geneva.

[25]. Republic of Ghana. (1969). Population Planning for National Progress and Prosperity - Ghana Population Policy. Accra, Ghana.

[26]. Shetty P, (2012) Grey matter: ageing in developing countries. The Lancet, 379(9823):1285-1287.

[27]. Knodel J and Chayovan N (2015) Population Ageing and the Well-Being of Older Persons in Thailand: Past Trends, Current Situation and Future Challenges.

[28]. Tawiah EO, (2011) Population Ageing in Ghana: A Profile and Emerging Issues, African Population Studies, Vol 25

[29]. APT, NA. (1993) Care of the elderly in Ghana: An emerging issue. Journal of Cross-Cultural Gerontology, 8: $301-312$. 